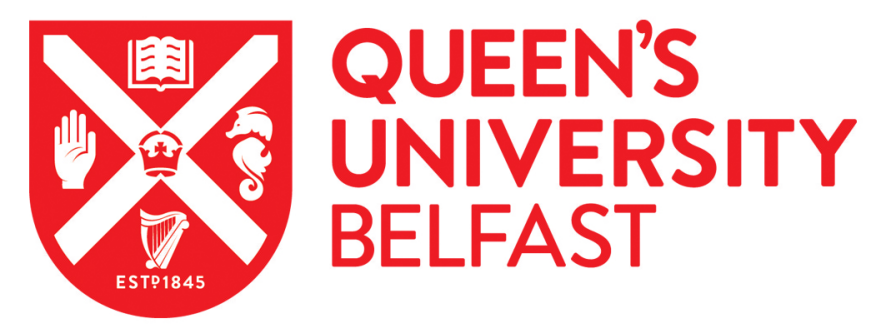

\title{
Clustering of metabolic syndrome risk factors and arterial stiffness in young adults: the Northern Ireland Young Hearts Project
}

Ferreira, I., Boreham, C., Twisk, J. W. R., Gallagher, A. M., Young, I., Murray, L., \& Stehouwer, C. D. A. (2007). Clustering of metabolic syndrome risk factors and arterial stiffness in young adults: the Northern Ireland Young Hearts Project. Journal of Hypertension, 25(5), 1009-1020.

Published in:

Journal of Hypertension

Queen's University Belfast - Research Portal:

Link to publication record in Queen's University Belfast Research Portal

\section{General rights}

Copyright for the publications made accessible via the Queen's University Belfast Research Portal is retained by the author(s) and / or other copyright owners and it is a condition of accessing these publications that users recognise and abide by the legal requirements associated with these rights.

Take down policy

The Research Portal is Queen's institutional repository that provides access to Queen's research output. Every effort has been made to ensure that content in the Research Portal does not infringe any person's rights, or applicable UK laws. If you discover content in the Research Portal that you believe breaches copyright or violates any law, please contact openaccess@qub.ac.uk. 


\title{
Clustering of metabolic syndrome risk factors and arterial stiffness in young adults: the Northern Ireland Young Hearts Project
}

\author{
Isabel Ferreira ${ }^{\mathrm{a}, \mathrm{b}}$, Colin A. Boreham ${ }^{\mathrm{c}}$, Jos W.R. Twisk ${ }^{\mathrm{d}}$, Alison M. Gallagher ${ }^{\mathrm{e}}$, \\ lan S. Young ${ }^{f}$, Liam J. Murray ${ }^{g}$ and Coen D.A. Stehouwer ${ }^{b}$
}

Objectives This study aimed to investigate whether the clustering of the risk factors of the metabolic syndrome (MetS) is associated with stiffness of central and peripheral arterial segments; whether these associations are similar in men and women; and whether insulin resistance and low-grade inflammation mediate any such associations.

Background Increased arterial stiffness may explain, at least in part, the increased cardiovascular and diabetes risk associated with the MetS. However, the mechanisms linking the MetS to an increased arterial stiffness are incompletely understood, and gender differences may exist.

Methods Cross-sectional analyses of data on $\mathbf{3 1 3}$ young men and women (mean age 23 years) from the Northern Ireland Young Hearts Project. Subjects were categorized according to the number of traits of the MetS; in addition a continuous MetS score was calculated. Arterial stiffness was assessed by measuring pulse wave velocity (PWV) in three arterial segments using a non-invasive optical method.

Results The prevalence of the MetS was similar for men (10.6\%) and women (10.5\%). After adjustment for potential confounders and other cardiovascular risk factors, PWV of the three arterial segments investigated increased with increasing traits of the MetS in women only. Women with the MetS, as compared to those without risk factors of the syndrome, had greater PWV of the aorto-iliac $(+14.0 \%$, $P=0.016)$, the aorto-radial $(+13.2 \%, P=0.010)$ and aorto-dorsalis pedis $(+11.8 \%, P=0.011)$ segments. A great deal (up to $75 \%$ ) of the association between the MetS and aortic-iliac PWV was mediated by heart rate, inflammation markers [C-reactive protein (CRP) and fibrinogen] and

\section{Introduction}

The metabolic syndrome (MetS), i.e. the clustering of central obesity, dyslipidaemia, elevated blood pressure and high fasting glucose levels, increases the risk of cardiovascular disease and, more markedly, of type 2 diabetes [1-4]. An adverse association between the MetS and prevalent [5-18] and incident [19,20] arterial stiffness have been hypothesized to explain, at least in part, such increased risk. Indeed, stiffness, particularly of central arterial segments (i.e. the aorta) predicts cardiovascular risk and mortality, notably in the general insulin resistance [homeostatic model assessment-insulin resistance (HOMA-IR)], whereas these variables did not explain much of the association between the MetS and PWV of the peripheral segments.

Conclusions Young women with the MetS show increased stiffness of peripheral and central arteries, a mechanism that may explain their increased cardiovascular risk. Low-grade inflammation, insulin resistance and sympathetic activation explain much of the adverse impact of the MetS on central, but not peripheral, arterial stiffness. J Hypertens 25:1009-1020 (C) 2007 Lippincott Williams \& Wilkins.

Journal of Hypertension 2007, 25:1009-1020

Keywords: arterial stiffness, epidemiology, insulin resistance, low-grade inflammation, metabolic syndrome, pulse wave velocity, young adults

aDepartment of Clinical Epidemiology and Medical Technology Assessment (KEMTA), 'Department of Internal Medicine, University Hospital Maastricht, Maastricht, The Netherlands, Institute for Sport and Health, University College Dublin, Dublin, Ireland, 'Department of Clinical Epidemiology and Biostatistics, Institute for Research in Extramural Research (EMGO), VU University Medical

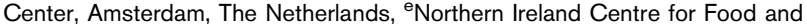
Health (NICHE), University of Ulster, Jordanstown, ${ }^{f}$ Centre for Clinical and Population Sciences and ${ }^{9}$ Department of Epidemiology and Community Health, Queen's University of Belfast, Belfast, Northern Ireland

Correspondence and requests for reprints to Isabel Ferreira, University Hospital Maastricht, Department of Clinical Epidemiology and Medical Technology Assessment (KEMTA), P.O. Box 5800, 6202 AZ Maastricht, The Netherlands Tel: +314338743 86; fax: +31433874419; e-mail: i.ferreira@epid.unimaas.nl

Received 22 August 2006 Revised 11 January 2007 Accepted 12 January 2007

See editorial commentary on page 935

population [21-23]. In addition, peripheral arterial stiffness has been associated with peripheral vascular disease [24,25], a relevant clinical outcome in the (pre-)diabetic population, although it may not have the same predictive value for fatal cardiovascular outcome as has central stiffness [26].

Most of the studies that have examined the association between the MetS and its components have focused particularly on one specific arterial segment, such as the aorta $[5,7,11,14,19,20]$, brachial-ankle segment 
$[6,10,12]$ and the lower limb [13], or one arterial site such as the brachial [18] and more often the carotid artery $[9,16,17]$. Exceptions are the studies of Schillaci et al. [15], who demonstrated the MetS to be associated with higher aortic but not upper limb arterial stiffness, and Ferreira et al. [8], who reported higher stiffness at the femoral than the carotid arteries. Whether the adverse associations of the MetS with arterial stiffness are similar between central and peripheral (i.e. upper and lower limb) arterial segments is therefore not known, and needs to be further investigated.

Several studies suggest that the cardiovascular morbidity/ mortality associated with the MetS and diabetes is higher in women than in men [27-31]. However, with regard to arterial stiffness, most of the studies investigating the impact of the MetS have undertaken sex-adjusted analyses $[5,7-9,11,13,15,16,18,20]$ or have been performed in single-sex cohorts [17,19], thereby not clarifying this issue. A further essential question is therefore whether the impact of the MetS on arterial stiffness differs between men and women, being stronger in the latter as suggested by some $[6,14]$.

Finally, the adverse association between the MetS and arterial stiffness raises important questions about the potential underlying pathological processes. The MetS is characterized by insulin resistance, a pro-thrombotic and pro-inflammatory state, endothelial dysfunction and sympathetic activation [1,3,32]. These features, which are inter-related, exert deleterious effects on the arterial wall, and may therefore mediate the MetS-arterial stiffness association [33]. Indeed, recent studies have highlighted the deleterious role inflammation may play in arterial stiffness [5,34-39], while low-grade inflammation was shown to partially mediate the association between adiposity, a major feature of the MetS, and arterial stiffness $[18,40]$. Whether low-grade inflammation and/or insulin resistance mediates the association between the MetS and arterial stiffness has, however, never been shown.

In view of these considerations, we investigated the associations between the clustering of traits of MetS (as well as each trait separately) and stiffness [assessed by pulse wave velocity (PWV)] of central and peripheral arterial segments; whether any such associations differ by gender; and the extent to which any such associations were mediated by markers of insulin resistance (HOMA-IR) and/or low-grade inflammation [C-reactive protein (CRP) and fibrinogen]. These questions were conducted in a population-based cohort study of young (20-25-year-old) and apparently healthy adults from Northern Ireland, which constitutes a suitable model for the study of the early steps of arterial stiffness and its determinants.

\section{Methods}

\section{Subjects and study design}

The Northern Ireland Young Hearts (YH) Project started in $1989 / 90$ by examining biological and behavioural risk factors for cardiovascular disease in a randomly selected sample ( $n=1015 ; 2 \%$ of total population) of school children (12 and 15 years) from Northern Ireland (YH1). The original 12-year-old population was followed up in 1992/93 (YH2), where complete data on 225 boys and 230 girls were obtained (corresponding to a $90 \%$ response rate) [41]. All participants in the original cohort were invited to participate in a third screening phase (YH3: October 1997-October 1999) when aged 20-25 years. Two hundred and fifty-one men and 238 women $(48.7$ and $51.3 \%$ of the original male and female cohort, respectively) attended the YH3 [42]. As compared to drop-outs, these participants were characterized, at YH1, by lower systolic blood pressure and body fatness, and more often belonged to a lower socio-economic class [43].

Arterial stiffness estimates were assessed for the first time during $\mathrm{YH} 3$, and valid measurements were obtained on 444 (224 women) participants. The current study reports on cross-sectional analyses (YH3) concerning 313 (153 women) individuals for whom complete data on arterial stiffness, risk factors of the MetS, insulin resistance and markers of low-grade inflammation were available. These participants did not differ from those not included $(n=131)$ with regard to arterial stiffness estimates and to the risk factors of the MetS and other covariates investigated (Table 1). Each participants provided written informed consent, and the study was approved by the Research Ethics Committee of the Queen's University of Belfast.

\section{Clinical and biochemical variables}

Participants were invited for an appointment at the university's research centre, where they underwent all clinical and biochemical measurements in one morning (3-4h). All measurements were obtained by trained nurses and research assistants and are described in detail below [41,42].

\section{Anthropometry}

Anthropometric measurements were obtained with participants wearing light indoor clothes and no shoes. Body weight was measured to the nearest $0.1 \mathrm{~kg}$ using an electronic balance (SECA, Hamburg, Germany) and standing height was measured to the nearest millimetre using a Harpenden portable stadiometer (Holtain, Crymych, Pembrokeshire, UK). Body mass index was computed as weight (in $\mathrm{kg}$ ) divided by height (in $\mathrm{m}^{2}$ ). Waist circumference was measured at the level midway between the lowest rib margin and the iliac crest, using a flexible steel tape and measuring to the nearest millimetre. 
Table 1 General characteristics of the subjects excluded versus those included in the present study

\begin{tabular}{|c|c|c|c|c|}
\hline Characteristics & \multicolumn{2}{|c|}{ Excluded $(n=131)$} & Included $(n=313)$ & $P$ value \\
\hline Male (\%) & 131 & 51.1 & 45.8 & 0.307 \\
\hline PWV aorto-radial (m/s) & 131 & $4.24(0.54)$ & $4.23(0.55)$ & 0.806 \\
\hline PWV aorto-dorsalis pedis $(\mathrm{m} / \mathrm{s})$ & 131 & $4.97(0.55)$ & $4.96(0.58)$ & 0.825 \\
\hline $\mathrm{BMI}\left(\mathrm{kg} / \mathrm{m}^{2}\right)$ & 131 & $24.1(3.9)$ & $23.8(3.7)$ & 0.370 \\
\hline LDL cholesterol $(\mathrm{mmol} / \mathrm{l})$ & 74 & $2.81(0.74)$ & $2.93(0.82)$ & 0.244 \\
\hline Triglycerides (mmol/l) & 74 & $0.84(0.54)$ & $0.78(0.38)$ & 0.248 \\
\hline Fasting plasma glucose $(\mathrm{mmol} / \mathrm{l})$ & 30 & $4.33(0.64)$ & $4.40(0.45)$ & 0.432 \\
\hline Fasting insulin $(\mu \mathrm{lU} / \mathrm{ml})$ & 71 & $10.0(7.0-12.5)$ & $10.5(8.0-15.0)$ & 0.066 \\
\hline HOMA-IR (arbitrary units) & 12 & $1.8(1.3-2.5)$ & $2.0(1.5-2.9)$ & 0.328 \\
\hline Systolic blood pressure $(\mathrm{mmHg})$ & 130 & $112.4(12.0)$ & $112.9(12.8)$ & 0.669 \\
\hline Diastolic blood pressure $(\mathrm{mmHg})$ & 130 & $74.1(10.3)$ & $73.6(9.2)$ & 0.661 \\
\hline Fibrinogen $(\mathrm{g} / \mathrm{l})$ & 82 & $2.70(0.82)$ & $2.66(0.61)$ & 0.571 \\
\hline
\end{tabular}

\# indicates exact number of subjects in whom data was available; BMI, body mass index; CRP, C-reactive protein; HDL, high-density lipoprotein; HOMA-IR, homeostatic model assessment-insulin resistance; LDL, low-density lipoprotein; PWV, pulse wave velocity; $\mathrm{VO}_{2}$ max, maximal oxygen uptake. Data are means (standard deviation) or median (inter-quartile range) or percentages.

\section{Blood pressure}

Blood pressure was measured twice from the right arm, using a Hawksley random zero sphygmomanometer, with the participant sitting quietly for at least $5 \mathrm{~min}$. Systolic blood pressure (SP; Korotkoff phase I) and diastolic blood pressure (DP; Korotkoff phase V) were recorded as the mean of the two values. Mean arterial pressure (MAP) was calculated as $(2 \mathrm{DP}+\mathrm{SP}) / 3$.

\section{Blood analyses}

Fasting (from midnight on the previous day) blood samples $(40 \mathrm{ml})$ were drawn from the antecubital vein. Total cholesterol and triglycerides from serum were measured using enzymatic assays (Boehringer Mannheim Ltd, Lewes, East Sussex, UK) on a Cobas Fara automated centrifugal analyser (Roche Products Ltd., Lewes, East Sussex, UK). High-density lipoprotein (HDL) cholesterol was measured by enzymatic assay following phosphotungstate precipitation. Low-density lipoprotein (LDL) cholesterol was calculated using the Friedewald formula. Fasting plasma glucose was measured using the glucose oxidase/p-aminophenazone pack (GOD/PAP) method (Randox Laboratories Ltd., Crumlin, Antrim, UK) on a Vitros 700 analyser (Ortho-Clinico Diagnostics Inc., High Wycombe, Bucks, UK). Serum insulin was measured by an enzyme-linked immunosorbent assay (ELISA; Abbott Imx) (Abbott Laboratories, Maidenhead, Berkshire, UK). The degree of insulin resistance was estimated by the homeostatic model assessment (HOMA-IR), which uses the product of fasting insulin concentration and the fasting glucose level divided by 22.5 [44]. Fibrinogen was assessed using an automated Clauss assay and high-sensitivity
C-reactive protein (CRP) was measured by an immunoturbidometric assay (Randox Laboratories Ltd.) on a Cobas Fara analyser. Quality control samples were included with every batch of samples and coefficients of variation (CVs) calculated. Both inter- and intra-batch $\mathrm{CVs}$ were within reasonable limits $(<10 \%$ and $<5 \%$ for the automated assays). For the lipid analyses the laboratory participated in a quality assurance scheme.

\section{Cardiorespiratory fitness}

Cardiorespiratory fitness was measured using a submaximal cycle ergometer test. Subjects were required to pedal at a steady pace $(50-70$ pedal revolutions/min) for the duration of the test, which normally lasted $15 \mathrm{~min}$. The workload was increased after each 3 -min period until a heart rate of approximately 170 beats $/ \mathrm{min}$ was achieved. Heart rate was averaged over the final $15 \mathrm{~s}$ of each workload with a Polar Vantage heart rate monitor (Polar Electro Oy, Kempele, Finland). Oxygen uptake was monitored throughout the test using an on-line respiratory Quinton QMC gas analyser (Quinton Instruments, Seattle, Washington, USA), and maximal oxygen uptake $\left(\mathrm{VO}_{2} \max \right)$ was predicted by extrapolation of $\mathrm{VO}_{2}$ at 170 beats/min to the age-adjusted estimated maximal heart rate, and expressed in $\mathrm{ml} / \mathrm{kg}$ per min.

\section{Smoking and alcohol consumption}

Smoking and alcohol consumption habits were assessed by a questionnaire, completed by participants in advance of their appointment and checked for completeness on the day of their appointment at the research centre. 


\section{Arterial stiffness}

All participants had refrained from smoking and drinking caffeine-containing beverages on the day the measurements were performed. After participants had been resting in a supine position for $15 \mathrm{~min}$ in a quiet, temperaturecontrolled room, a single trained investigator obtained measurements of pulse wave velocity (PWV) in three arterial segments (all on the left side of the body) with the use of a non-invasive optical method. This method determines the transit time the wave of dilatation (propagated in the arterial wall as a result of the pressure wave generated by contraction of the left ventricle) takes to arrive at a distal site over a known distance. The transittime measurements (in $\mathrm{ms}$ ) were performed with a photoplethysmographic probe and were triggered by the R-wave of the ECG. The distances between the proximal carotid to the femoral, the dorsalis pedis and the radial arteries (to $0.1 \mathrm{~cm}$ ) were then divided by the transit time the pulse wave took to arrive at each of these arterial sites, to determine PWV (in $\mathrm{m} / \mathrm{s}$ ) of the aorto-iliac, aorto-dorsalis pedis and aorto-radial segments, respectively [45-47]. In some participants it was not possible to obtain PWV measurements of adequate quality (due to attenuation of the optical signal by subcutaneous fat or because of difficulty in assessing the artery position). According to the protocol's quality criteria, estimations of transit time based on fewer than 10 cycles, or those in which the CV was greater than $20 \%$, were therefore rejected (in 31, 25 and 29 participants for the aorto-iliac, aorto-radial and aorto-dorsalis pedis segments, respectively); measurement of PWV in all three arterial segments were thus obtained in a total of 444 participants.

\section{Definition of the metabolic syndrome}

Because all traits of the MetS show a graded association with cardiovascular risk, the rationale to set specific cutoff points for risk has been disputed [32], especially for young adults in whom the level where risk increases may be spurious [48]. We therefore used two approaches to define the MetS. First, participants were assigned to four categories according to the number of risk factors/traits present $(0,1,2$ and $\geq 3)$; risk was defined by values above the sex-specific 80 th percentile (below the 20th percentile for HDL cholesterol) of the risk factors included in National Cholesterol Education Program (NCEP) [3] and the International Diabetes Federation (IDF) definitions of the syndrome [1], (i.e. waist circumference, systolic or diastolic blood pressure, HDL cholesterol, triglycerides, and fasting plasma glucose). The cut-off values thereby derived are presented in Table 2. The presence of the MetS was identified when three or more of the above traits were present. This allocation of participants was then validated by examining whether the observed risk factor clustering (three or more) occurred to levels above those that could be dictated by chance alone. The expected degree of risk factor clustering was estimated by calculating the probability of $r$ occurrences for $n$ risk factors when
Table 2 Sex-specific cut-off values for each risk factor of the metabolic syndrome corresponding to the highest (lowest for HDL cholesterol) quintile

\begin{tabular}{lll}
\hline Risk factor of the metabolic syndrome & Men & Women \\
\hline Systolic/diastolic blood pressure $(\mathrm{mmHg})$ & $\geq 130 / 85$ & $\geq 115 / \geq 80$ \\
Waist circumference $(\mathrm{cm})$ & $\geq 90.2$ & $\geq 81.3$ \\
Triglycerides $(\mathrm{mmol} / \mathrm{l})$ & $\geq 1.07$ & $\geq 1.01$ \\
HDL cholesterol $(\mathrm{mmol} / \mathrm{l})$ & $\leq 1.05$ & $\leq 1.12$ \\
Fasting plasma glucose $(\mathrm{mmol} / \mathrm{l})$ & $\geq 4.8$ & $\geq 4.6$ \\
\hline
\end{tabular}

HDL, high-density lipoprotein.

the probability of each occurrence was 0.20 , using the binomial formula:

$$
\left(\begin{array}{l}
n \\
r
\end{array}\right)(0.2)^{r}(0.8)^{n-r}
$$

The expected versus the observed frequencies of participants with $0,1,2$, and 3 or more traits of the MetS were 32.8 versus $37.7 \%, 41.0$ versus $29.1 \%, 20.5$ versus $22.7 \%$, and 5.8 versus $10.5 \%$, respectively. The observed prevalence of the clustering of three or more traits (i.e. the MetS) was $1.8(1.2-2.4)$ times higher than could be expected by chance alone $(P=0.006)$. Secondly, we also computed a continuous MetS score as follows: for each of the traits of the MetS a sex-specific z-score [(value sample mean)/sample SD] was computed; the HDL cholesterol $z$-score was multiplied by -1 to indicate increasing risk with increasing value; the z-scores of systolic and diastolic blood pressure were averaged to estimate an overall blood pressure $z$-score. The resulting five $z$-scores were then averaged to indicate the MetS score [49]. This approach avoids the loss of information that otherwise would occur with the use of dichotomized variables, and may therefore be more suitable for aetiological research.

\section{Statistical analysis}

All analyses were carried out with the Statistical Package of Social Sciences, 12.01 for Windows (SPSS Inc., Chicago, Illinois, USA). Linear trends of baseline characteristics across the number of traits of the MetS were investigated with the use of chi-squared (categorical variables) and analysis of covariance (ANCOVA) (continuous variables) tests. The PWV of the aorto-iliac, the aorta-dorsalis pedis and the aortoradial segments was compared across categories of MetS traits in the whole study population and in men and women separately (because of significant sex interactions). These comparisons were adjusted for known confounders of arterial stiffness (sex, age, body weight and height and MAP) as well as other known cardiovascular risk factors (LDL cholesterol, smoking and alcohol consumption status, and cardiorespiratory fitness levels). 
We then used multiple linear regression analyses to investigate the association between the continuous MetS score (and each of its traits) on the one hand (main determinants), and PWV of the three arterial segments investigated on the other hand (outcomes). Each trait of the MetS was expressed as sex-specific $z$-scores to facilitate comparison of the strengths of associations with arterial stiffness between the different traits. These analyses were initially adjusted for age, body weight and height, and MAP (model 1). This model was then successively extended with further adjustments for other cardiovascular risk factors to ascertain the extent to which the observed associations between MetS score and the arterial stiffness outcomes were confounded and/or mediated by these variables (models $2-7$ ); this was done by evaluating the magnitude of changes in the regression coefficients, which were considered relevant whenever higher than $10 \%$.

\section{Results}

Table 3 shows the general characteristics of the study population according to the number of traits of the MetS, in men and women separately. The prevalence of the MetS did not differ between men and women (10.6 versus $10.5 \%, P=0.962$, respectively). Both were characterized by a worsening cardiovascular risk profile with increasing traits of the MetS. However, CRP and fibrinogen levels increased significantly with increasing traits of the MetS in women only $(P$ values sex-interaction $=0.019$ and 0.005 , respectively).

\section{Clustering of risk factors of the metabolic syndrome and arterial stiffness}

The PWV of all three arterial segments investigated increased with increasing traits of the MetS in the whole population, but these trends were significant in women only (Table 4$)(P$ values for sex-interactions $<0.05$ for all segments). Although the absolute differences in PWV (in $\mathrm{m} / \mathrm{s}$ ) associated with the clustering of three or more traits of the MetS were higher with regard to the peripheral muscular segments (aorto-radial and aorto-dorsalis pedis) than the central elastic segment (aorto-iliac) segment $(0.53$ and $0.52 \mathrm{~m} / \mathrm{s}$ versus $0.40 \mathrm{~m} / \mathrm{s}$, respectively), the relative differences in PWV were comparable for all segments: women with the MetS, compared to those without traits of the syndrome, had $14.1 \%$ greater stiffness of the aorto-iliac segment, $13.2 \%$ of the aorto-radial segment and $11.3 \%$ of the aorto-dorsalis pedis segment (Fig. 1).

The continuous MetS score was also significantly associated with increased arterial stiffness of all three arterial segments in women only (Table 5). In women, higher blood pressure was the strongest determinant of increased arterial stiffness in all segments; in addition, glucose levels were also significantly associated with increased stiffness of all arterial segments and abdominal obesity was an additional determinant of stiffness of the aorto-dorsalis pedis segment. In men, higher blood pressure and abdominal obesity were the only traits of the MetS to be associated with greater PWV of the aorto-iliac and of the aorto-dorsalis pedis segments, respectively.

\section{Confounding and/or mediating role of other risk variables in the associations between the metabolic syndrome and arterial stiffness}

The confounding and/or mediating role of other risk variables in the associations between the MetS and arterial stiffness estimates is described in detail below for women only, given the fact that no significant associations were primarily found in men (Table 6).

In women, the associations between the MetS score and arterial stiffness were not disturbed by other traditional risk factors (Table 6, model 2). In contrast, the strength of the association between the MetS score and the PWV of the aorto-iliac segment decreased when further adjustments for heart rate $(-30 \%)$, fibrinogen $(-20 \%)$, CRP $(-12 \%)$, combined inflammation score $(-22 \%)$ and HOMA-IR $(-11 \%)$ were included in the models. Heart rate and HOMA-IR also reduced the strength of the association between the MetS and PWV of the aortoradial segment ( -20 and 39\% respectively). Only heart rate reduced the strength of the association between the MetS score and PWV of the aorto-dorsalis pedis segment $(-25 \%)$. The fully adjusted model (Table 6 , model 7 ) explained up to three-quarters of the association between the MetS and PWV of the aorto-iliac segment, and onethird of the association between the MetS and PWV of the aorto-radial segment. The association between the MetS score and PWV of the aorto-dorsalis pedis remained significant and was even stronger after adjustments for all the covariates considered.

\section{Discussion}

The MetS is thought to be a driver of current diabetes and cardiovascular disease (CVD) epidemics and has become a major public health challenge around the world $[1,3]$. How the MetS increases the risk of CVD is incompletely understood. Our study, in keeping with others [5-20], suggests that increased arterial stiffness may be involved. Indeed, increased arterial stiffness leads not only to changes within the vascular wall (i.e. fragmentation and degeneration of elastin and increases in collagen synthesis) but also to adverse haemodynamic effects, such as increased systolic and pulse pressure, which enhance the risk of stroke, heart failure and death [50-52]. We now show that the adverse associations between the clustering of risk factors of the MetS and arterial stiffness are already evident in young women but not in men, and that they affect the arterial tree throughout (i.e. the central and peripheral arterial segments). Our results also show that low-grade inflammation, elevated resting heart rate and insulin resistance explain much of 


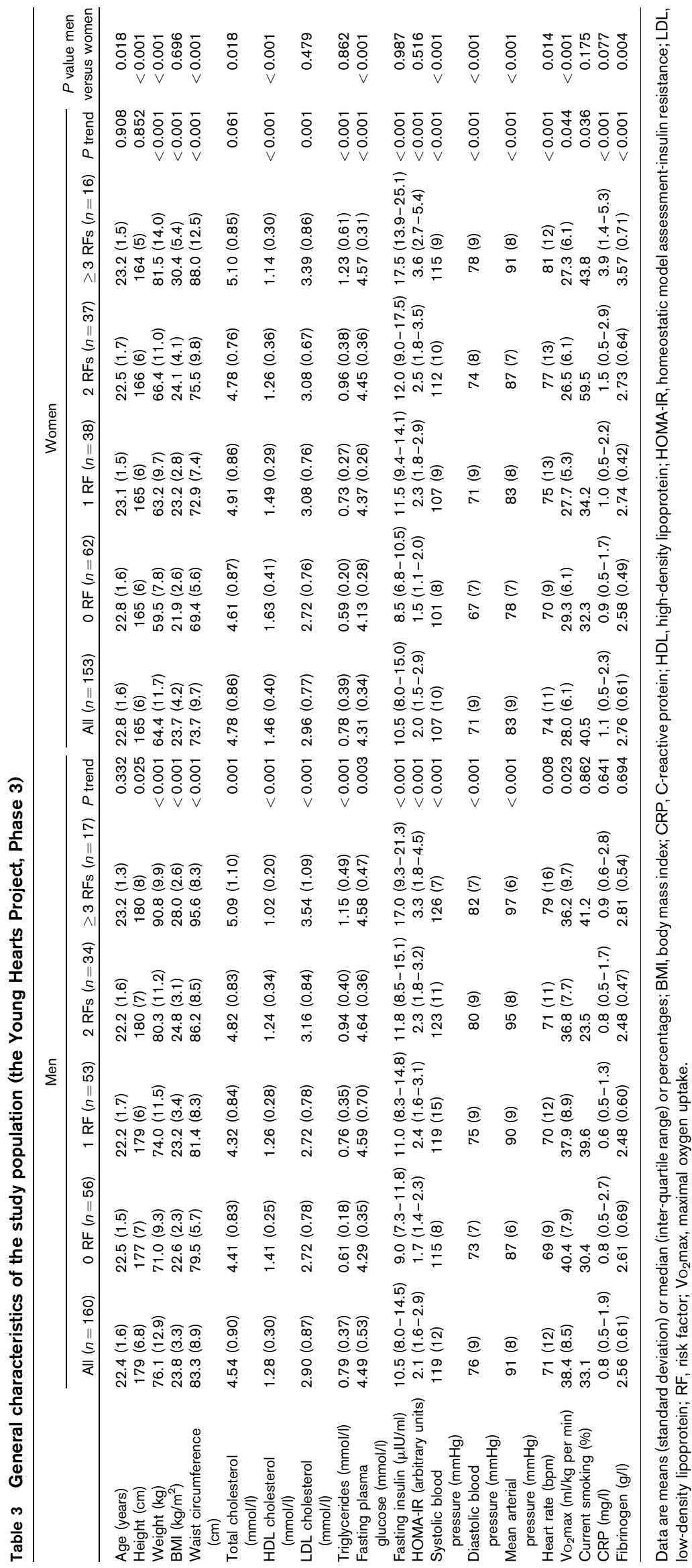




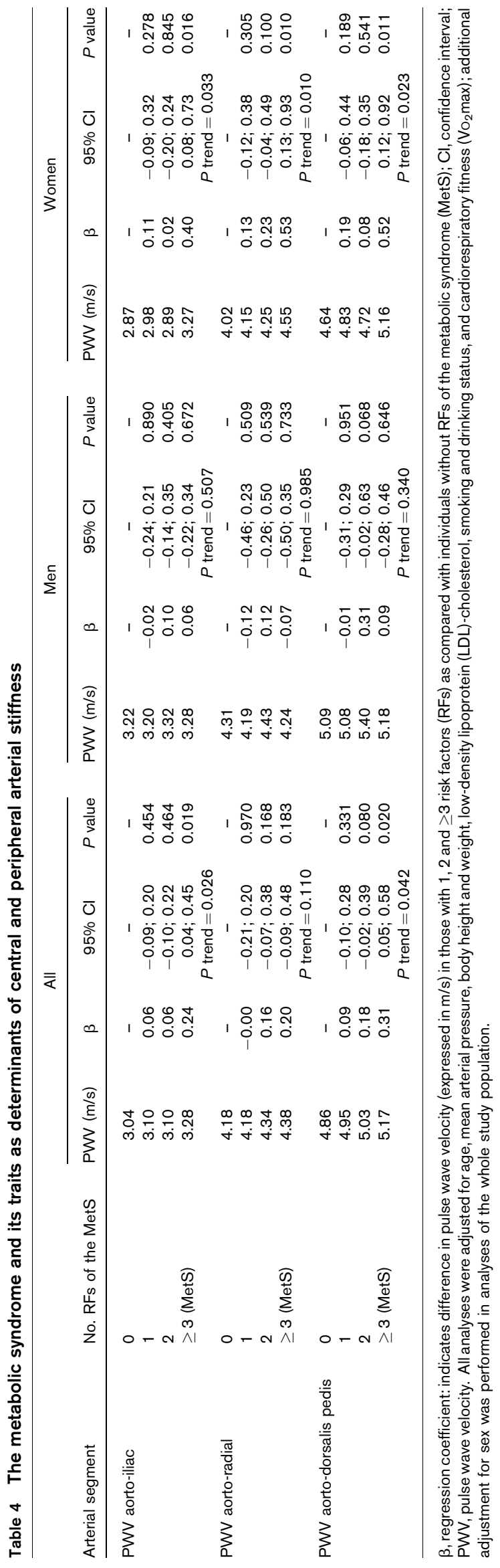

the association between the MetS and stiffness of the central elastic but not of peripheral muscular arterial segments. This is the first population-based study to report associations between the MetS and stiffness of central and peripheral (upper and lower limbs) arterial segments in the same cohort, and to examine these in men and women separately.

Several studies suggest that the cardiovascular morbidity/ mortality risk associated with the MetS and diabetes is higher in women than in men [27-30]. Our finding that the MetS has a deleterious impact on arterial stiffness in young women but not in young men may thus explain the higher cardiovascular risk in women. This observation is in line with greater left ventricular hypertrophy and impaired function (known consequences of arterial stiffness), observed in women with MetS compared to men [31]. We have tested gender differences specifically, and differences found were in agreement with two other studies with a similar purpose $[6,14]$. It is noteworthy that such gender differentiation would have not been depicted if data were analysed for men and women combined (with further adjustment for sex), as in most of the studies reported so far $[5,7-9,11,13,15,16,18,20]$. In addition, we found that the cardiovascular risk profile across increasing traits of the MetS differs between men and women with regard to inflammatory markers (CRP and fibrinogen), which were higher in women. These findings are in keeping with the results of other population-based studies [53-55]. It is thus plausible that the elevated low-grade inflammation related to the MetS could act as an underlying mechanism driving the increased arterial stiffness in these women. Indeed, up to $22 \%$ of the association between the MetS (score) and central arterial stiffness in women was explained by lowgrade inflammation. All together these findings support the view that the increased cardiovascular risk in women with MetS/diabetes may be due to more pronounced effect of the MetS on the vascular wall, probably related to a heavier burden of concomitant risk factors (e.g. inflammation). A further explanation for women's increased risk may lie in poorer risk factor control as compared to men [56]. Our findings, therefore, emphasize the need of a more intensive awareness and monitoring of risk factor clustering in women, especially at a young age.

The function and structure of the arterial system is heterogeneous and differs markedly between central elastic arteries (aorta and major branches), which mainly carry out a cushioning function, and muscular peripheral arteries (upper and lower limbs), which have a predominantly conduit function [57]. The central (elastic) arteries are characterized by lower stiffness and high susceptibility to ageing and blood pressure, whereas the peripheral part of the arterial tree is characterized by higher stiffness and susceptibility to vasoactive substances [33,52]. 
Fig. 1
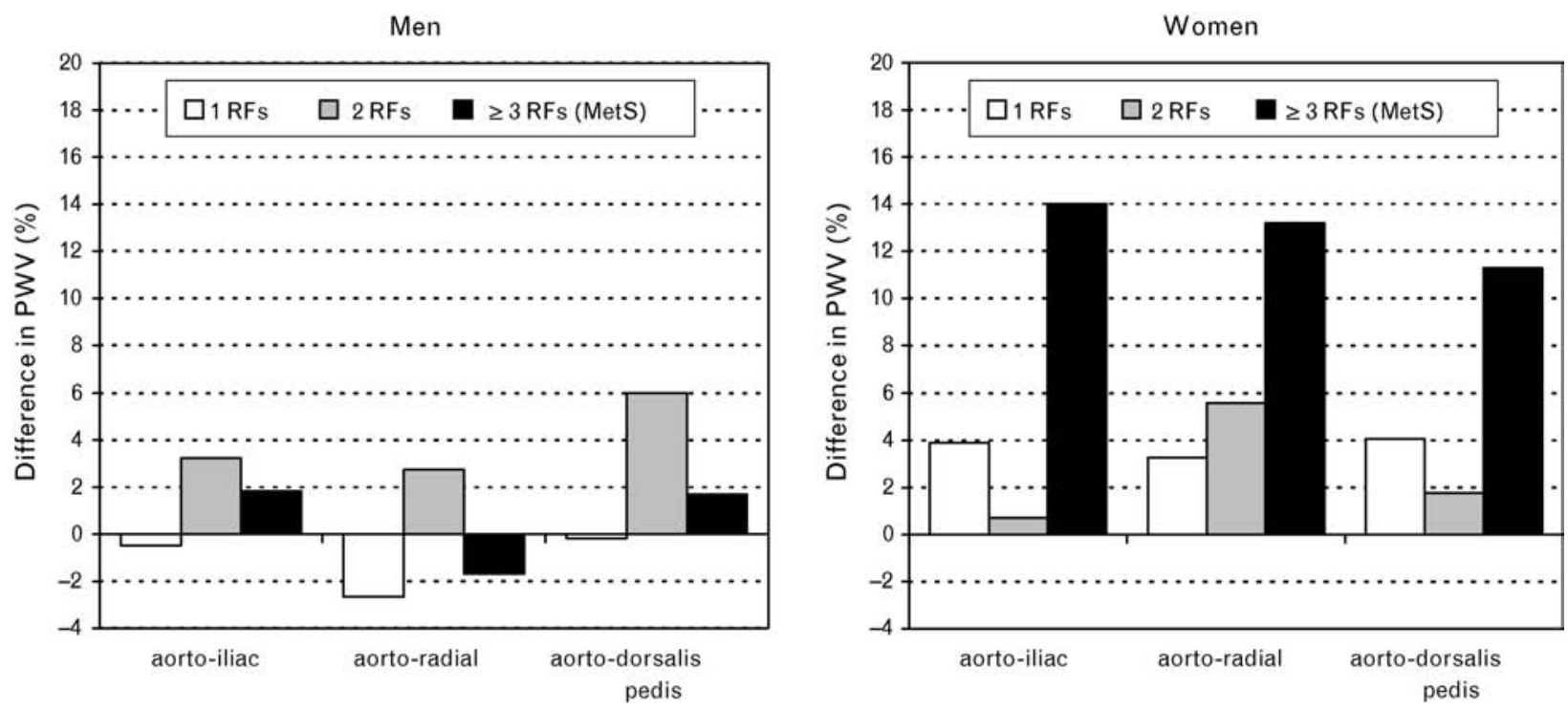

Relative differences in pulse wave velocity (PWV) across categories of risk factors (RFs) of the metabolic syndrome (MetS) as compared to no risk factors. Data are adjusted for age, mean arterial pressure, body height and weight, low-density lipoprotein (LDL)-cholesterol, smoking and drinking status, and cardiorespiratory fitness.

Differences in the basic architecture of arteries at the extracellular matrix level (i.e. in the proximal aorta, elastin is the dominant component, whereas in the distal aorta, the collagen-to-elastin ratio is reversed, and in peripheral arteries, collagen predominates) may explain such different susceptibilities [52]. Our findings suggest that the adverse effects of the MetS, at least in women, are similar throughout the arterial tree. Although increased stiffness of peripheral arterial segments may not carry the same burden in terms of cardiovascular mortality [26], it is nevertheless related to peripheral arterial disease $[24,25]$, a very frequent and clinically relevant outcome in the diabetic population. Importantly, however, the peripheral and central compartments of the arterial tree are linked: increased stiffness at peripheral sites leads to earlier pulse wave reflections, resulting in an augmented systolic and a reduced diastolic pressure and, hence, an increased pulse pressure (and cardiovascular risk) [52].

In the present study we found that elevated blood pressure and glucose levels were the main players affecting arterial stiffness of all arteries in women, whereas abdominal obesity was mainly associated with increased stiffness of the lower limb arteries (and this in

Table 5 Associations between the metabolic syndrome (MetS) score and each of its traits and central and peripheral arterial stiffness

\begin{tabular}{|c|c|c|c|c|c|c|c|c|c|}
\hline \multirow[b]{2}{*}{ Risk factors } & \multicolumn{3}{|c|}{ Aorto-iliac segment } & \multicolumn{3}{|c|}{ Aorto-radial segment } & \multicolumn{3}{|c|}{ Aorto-dorsalis pedis segment } \\
\hline & $\beta$ & $95 \% \mathrm{Cl}$ & $P$ value & $\beta$ & $95 \% \mathrm{Cl}$ & $P$ value & $\beta$ & $95 \% \mathrm{Cl}$ & $P$ value \\
\hline \multicolumn{10}{|l|}{ Metabolic syndrome score } \\
\hline Men & 0.086 & $-0.064 ; 0.237$ & 0.258 & 0.020 & $-0.223 ; 0.263$ & 0.873 & 0.160 & $-0.049 ; 0.369$ & 0.133 \\
\hline Women & 0.165 & $0.004 ; 0.327$ & 0.045 & 0.250 & $0.052 ; 0.448$ & 0.014 & 0.239 & $0.042 ; 0.436$ & 0.018 \\
\hline \multicolumn{10}{|l|}{ Risk factors of the MetS } \\
\hline \multicolumn{10}{|l|}{ Men } \\
\hline Blood pressure $^{a}$ & 0.726 & $0.165 ; 1.287$ & 0.012 & 0.467 & $-0.451 ; 1.385$ & 0.317 & 0.369 & $-0.437 ; 1.165$ & 0.361 \\
\hline Waist circumference & 0.053 & $-0.090 ; 0.196$ & 0.466 & -0.021 & $-0.251 ; 0.209$ & 0.857 & 0.265 & $0.070 ; 0.460$ & 0.008 \\
\hline HDL-cholesterol & -0.028 & $-0.087 ; 0.031$ & 0.354 & -0.040 & $-0.055 ; 0.135$ & 0.404 & -0.031 & $-0.114 ; 0.051$ & 0.454 \\
\hline Triglycerides & 0.046 & $-0.013 ; 0.105$ & 0.129 & 0.052 & $-0.043 ; 0.148$ & 0.278 & 0.038 & $-0.045 ; 0.120$ & 0.369 \\
\hline Fasting plasma glucose & -0.022 & $-0.079 ; 0.035$ & 0.451 & 0.002 & $-0.090 ; 0.094$ & 0.968 & 0.004 & $-0.075 ; 0.084$ & 0.914 \\
\hline \multicolumn{10}{|l|}{ Women } \\
\hline Blood pressure $^{a}$ & 0.532 & $0.020 ; 1.044$ & 0.042 & 0.883 & $0.259 ; 1.507$ & 0.006 & 0.559 & $-0.069 ; 1.187$ & 0.081 \\
\hline Waist circumference & 0.097 & $-0.045 ; 0.240$ & 0.180 & 0.055 & $-0.122 ; 0.232$ & 0.539 & 0.202 & $0.029 ; 0.374$ & 0.022 \\
\hline HDL-cholesterol & 0.007 & $-0.057 ; 0.070$ & 0.839 & 0.045 & $-0.123 ; 0.33$ & 0.253 & -0.046 & $-0.124 ; 0.031$ & 0.239 \\
\hline Triglycerides & 0.040 & $-0.023 ; 0.104$ & 0.210 & 0.010 & $-0.068 ; 0.089$ & 0.796 & 0.011 & $-0.067 ; 0.089$ & 0.777 \\
\hline Fasting plasma glucose & 0.064 & $0.001 ; 0.126$ & 0.047 & 0.108 & $0.032 ; 0.185$ & 0.006 & 0.074 & $-0.003 ; 0.151$ & 0.058 \\
\hline
\end{tabular}

$\mathrm{Cl}$, confidence interval; HDL, high-density lipoprotein. $\beta$, regression coefficient: indicates change in pulse wave velocity (expressed in $\mathrm{m} / \mathrm{s}$ ) per $1 \mathrm{SD}$ deviation increase in independent variable. ${ }^{a}$ Blood pressure represents the overall blood pressure $z$-score calculated as the average of systolic and diastolic blood pressure $z$-scores.All analyses are adjusted for age, gender, body height and weight, and mean arterial pressure. 


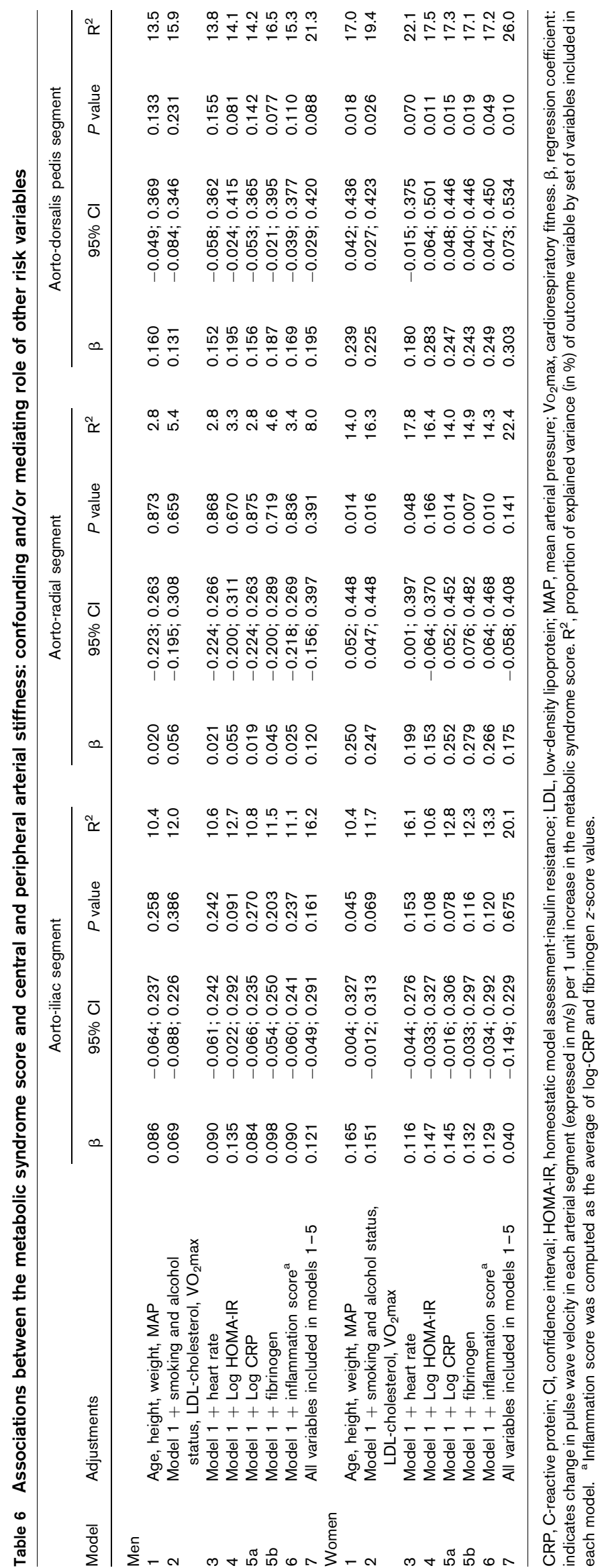


both men and women). Dyslipidaemia (i.e. elevated triglycerides and reduced HDL cholesterol) was not significantly associated with any arterial stiffness outcome investigated in the present study. This supports the view that not all the traits included in the MetS carry the same burden on arterial stiffness [7,15]. Arterial stiffness is both cause and consequence of blood pressure [58], which explains the predominant role of blood pressure observed in our analyses that, worthy of note, were adjusted for MAP. Nevertheless, accentuated progression of arterial stiffness in those with the MetS was shown to be independent of MAP [20], suggesting accelerated arterial ageing related to the cardiovascular risk factor clustering.

The adverse association between the MetS and arterial stiffness raises important questions about the potential underlying pathological processes. These may involve some effects of obesity and/or insulin resistance (the underlying features of the syndrome) on the vascular wall, including endothelial dysfunction, low-grade inflammation and sympathetic activation [33]. The mediating effects of some of these potential mechanisms were investigated, for the first time, in the present study. We showed that insulin resistance, low-grade inflammation and elevated heart rate (which may reflect sympathetic activation), combined, explained much of the MetS-central arterial stiffness association in women. However, the increased stiffness of the peripheral (i.e. muscular) part of the arterial tree (in particular the lower limb) was relatively undisturbed by these variables. Other factors not explored in the current study may thus explain the increased stiffness of muscular vessels. For instance, increased levels of adipocytokines [e.g. interleukin-6 (IL-6), tumour necrosis factor- $\alpha$ (TNF- $\alpha$ ), adiponectin] [40,59] or fat-tissue derived hormone leptin [60] could play a role. This is sustained by the observation that abdominal adiposity was mainly associated with arterial stiffness of the lower limb segment. Whether these factors preferentially affect the peripheral rather than the central part of the arterial tree, needs to be further investigated, however. Finally, because increased fasting glucose levels were associated with greater stiffness in all arterial segments investigated, it is also possible that hyperglycaemia-related non-enzymatic glycation of matrix proteins and the accumulation of glycation end products within the vessel wall would constitute another explanatory mechanism. Given the young age of the current study population and the 'normal' levels of fasting glucose observed, such an operative mechanism would be remarkable, and therefore warrants further investigation.

There are limitations to our study that warrant mentioning. The cross-sectional design does not allow us to draw conclusions in terms of causality. Our results were obtained in a young adult, white and apparently healthy population, and therefore inferences to older individuals, other ethnicities and high-risk populations should be made with caution. Finally, the cut-off values obtained based on the population distribution values of each risk factor of the MetS, may have been too liberal as compared to the cut-off values proposed by the NCEP or IDF definitions. Indeed, the prevalence of the metabolic syndrome as defined according to those definitions would have been 1.6 and $2.5 \%$, respectively (which represents a limited power to address the research questions posed in the present study). The prevalence of the MetS reported herein is thus an overestimation of the prevalence had those definitions been used instead. However, our study was aetiological in nature, i.e. its main purpose was to investigate the extent to which the clustering of risk factors of the MetS impact on arterial stiffness of central and peripheral segments of the arterial tree, and to study potential explanatory mechanisms for such associations. We have, nevertheless, shown that the clustering of three or more risk factors was considerably higher than chance alone would have dictated, suggesting that the cut-off values used in the current study were appropriate to identify those young individuals with a worse risk profile characteristic of the MetS.

In conclusion, we have shown that, in young women, the MetS is associated with increased central and peripheral arterial stiffness. Insulin resistance, low-grade inflammation and increased resting heart rate explained much of the MetS-central stiffness association, but other mechanisms, that warrant further investigation, may explain the adverse impact of the MetS on peripheral stiffness. These findings, obtained in a young and apparently healthy population, illustrate the early steps of arterial stiffening in those with moderate increases in metabolic risk factors, and therefore emphasize the importance of primary prevention of the MetS.

\section{Acknowledgements}

The British Heart Foundation and the Wellcome Trust supported the Northern Ireland Young Hearts Study. I.F. was supported by a post-doctoral research grant from the Foundation for Science and Technology of Portugal (Grant reference: SFRH/BPD/26367/2006).

There were no potential conflicts of interest.

\section{References}

1 Alberti G, Zimmet P, Shaw J. Metabolic syndrome - a new worldwide definition. A Consensus Statement from the International Diabetes Federation. Diabet Med 2006; 23:469-480.

2 Ford ES. Risks for all-cause mortality, cardiovascular disease, and diabetes associated with the metabolic syndrome: a summary of the evidence. Diabetes Care 2005; 28:1769-1778.

3 Grundy SM. Metabolic syndrome: connecting and reconciling cardiovascular and diabetes worlds. J Am Coll Cardiol 2006; 47:10931100.

4 Wannamethee SG, Shaper AG, Lennon L, Morris RW. Metabolic syndrome vs Framingham Risk Score for prediction of coronary heart disease, stroke, and type 2 diabetes mellitus. Arch Intern Med 2005; 165:2644-2650. 
5 Ahluwalia N, Drouet L, Ruidavets JB, Perret B, Amar J, Boccalon H, et al. Metabolic syndrome is associated with markers of subclinical atherosclerosis in a French population-based sample. Atherosclerosis 2006; 186:345-353.

6 Choi KM, Lee KW, Seo JA, Oh JH, Kim SG, Kim NH, et al. Relationship between brachial-ankle pulse wave velocity and cardiovascular risk factors of the metabolic syndrome. Diabetes Res Clin Pract 2004; 66:57-61.

7 Czernichow S, Bertrais S, Blacher J, Oppert JM, Galan P, Ducimetiere P et al. Metabolic syndrome in relation to structure and function of large arteries: a predominant effect of blood pressure. A report from the SU. VI. MAX. Vascular Study. Am J Hypertens 2005; 18:1154-1160.

8 Ferreira I, Henry RM, Twisk JW, van Mechelen W, Kemper HC, Stehouwer $\mathrm{CD}$. The metabolic syndrome, cardiopulmonary fitness, and subcutaneous trunk fat as independent determinants of arterial stiffness: the Amsterdam Growth and Health Longitudinal Study. Arch Intern Med 2005; 165:875882.

9 lannuzzi A, Licenziati MR, Acampora C, Renis M, Agrusta M, Romano L, et al. Carotid artery stiffness in obese children with the metabolic syndrome. Am J Cardiol 2006; 97:528-531.

10 Li S, Chen W, Srinivasan SR, Berenson GS. Influence of metabolic syndrome on arterial stiffness and its age-related change in young adults: the Bogalusa Heart Study. Atherosclerosis 2005; 180:349-354.

11 Mule G, Cottone S, Mongiovi R, Cusimano P, Mezzatesta G, Seddio G, et al. Influence of the metabolic syndrome on aortic stiffness in never treated hypertensive patients. Nutr Metab Cardiovasc Dis 2006; 16:5459.

12 Nakanishi N, Shiraishi T, Wada M. Brachial-ankle pulse wave velocity and metabolic syndrome in a Japanese population: the Minoh study. Hypertens Res 2005; 28:125-131.

13 O'Neal DN, Dragicevic G, Rowley KG, Ansari MZ, Balazs N, Jenkins A, Best JD. A cross-sectional study of the effects of type 2 diabetes and other cardiovascular risk factors on structure and function of nonstenotic arteries of the lower limb. Diabetes Care 2003; 26:199-205.

14 Protogerou AD, Blacher J, Aslangul E, Le Jeunne C, Lekakis J, Mavrikakis M, Safar ME. Gender influence on metabolic syndrome's effects on arterial stiffness and pressure wave reflections in treated hypertensive subjects. Atherosclerosis [Epub ahead of print]

15 Schillaci G, Pirro M, Vaudo G, Mannarino MR, Savarese G, Pucci G, et al. Metabolic syndrome is associated with aortic stiffness in untreated essential hypertension. Hypertension 2005; 45:1078-1082.

16 Scuteri A, Najjar SS, Muller DC, Andres R, Hougaku H, Metter EJ, Lakatta EG. Metabolic syndrome amplifies the age-associated increases in vascular thickness and stiffness. J Am Coll Cardio/ 2004; 43:1388-1395.

17 van Popele NM, Westendorp IC, Bots ML, Reneman RS, Hoeks AP, Hofman A, et al. Variables of the insulin resistance syndrome are associated with reduced arterial distensibility in healthy non-diabetic middle-aged women. Diabetologia 2000; 43:665-672.

18 Whincup PH, Gilg JA, Donald AE, Katterhorn M, Oliver C, Cook DG, Deanfield JE. Arterial distensibility in adolescents: the influence of adiposity, the metabolic syndrome, and classic risk factors. Circulation 2005; 112:1789-1797.

19 Nakanishi N, Suzuki K, Tatara K. Clustered features of the metabolic syndrome and the risk for increased aortic pulse wave velocity in middle-aged Japanese men. Angiology 2003; 54:551-559.

20 Safar ME, Thomas F, Blacher J, Nzietchueng R, Bureau JM, Pannier B, Benetos A. Metabolic syndrome and age-related progression of aortic stiffness. J Am Coll Cardiol 2006; 47:72-75.

21 Mattace-Raso FU, van der Cammen TJ, Hofman A, van Popele NM, Bos ML, Schalekamp MA, et al. Arterial stiffness and risk of coronary heart disease and stroke: the Rotterdam Study. Circulation 2006; 113:657-663.

22 Sutton-Tyrrell K, Najjar SS, Boudreau RM, Venkitachalam L, Kupelian V, Simonsick EM, et al. Elevated aortic pulse wave velocity, a marker of arterial stiffness, predicts cardiovascular events in well-functioning older adults. Circulation 2005; 111:3384-3390.

23 Willum-Hansen T, Staessen JA, Torp-Pedersen C, Rasmussen S, Thijs L, Ibsen H, Jeppesen J. Prognostic value of aortic pulse wave velocity as index of arterial stiffness in the general population. Circulation 2006; 113:664-670.

24 Kizu A, Koyama H, Tanaka S, Maeno T, Komatsu M, Fukumoto S, et al. Arterial wall stiffness is associated with peripheral circulation in patients with type 2 diabetes. Atherosclerosis 2003; 170:87-91.

25 Taniwaki $\mathrm{H}$, Shoji $\mathrm{T}$, Emoto $\mathrm{M}$, Kawagishi $\mathrm{T}$, Ishimura $\mathrm{E}$, Inaba M, et al. Femoral artery wall thickness and stiffness in evaluation of peripheral vascular disease in type 2 diabetes mellitus. Atherosclerosis 2001; 158:207-214.

26 Pannier B, Guerin AP, Marchais SJ, Safar ME, London GM. Stiffness of capacitive and conduit arteries: prognostic significance for end-stage renal disease patients. Hypertension 2005; 45:592-596.
27 Hunt KJ, Resendez RG, Williams K, Haffner SM, Stern MP. National Cholesterol Education Program versus World Health Organization metabolic syndrome in relation to all-cause and cardiovascular mortality in the San Antonio Heart Study. Circulation 2004; 110:1251-1257.

28 DECODE Study Group. Gender difference in all-cause and cardiovascular mortality related to hyperglycaemia and newly-diagnosed diabetes. Diabetologia 2003; 46:608-617.

29 McNeill AM, Rosamond WD, Girman CJ, Golden SH, Schmidt MI, East HE et al. The metabolic syndrome and 11-year risk of incident cardiovascular disease in the atherosclerosis risk in communities study. Diabetes Care 2005; 28:385-390.

30 Saely $\mathrm{CH}$, Aczel S, Marte T, Langer P, Hoefle G, Drexel H. The metabolic syndrome, insulin resistance, and cardiovascular risk in diabetic and nondiabetic patients. J Clin Endocrinol Metab 2005; 90:56985703.

31 Schillaci G, Pirro M, Pucci G, Mannarino MR, Gemelli F, Siepi D, et al. Different impact of the metabolic syndrome on left ventricular structure and function in hypertensive men and women. Hypertension 2006; 47:881886.

32 Kahn R, Buse J, Ferrannini E, Stern M. The metabolic syndrome: time for a critical appraisal: joint statement from the American Diabetes Association and the European Association for the Study of Diabetes. Diabetes Care 2005; 28:2289-2304

33 Stehouwer CD, Ferreira I. Diabetes, lipids and other risk factors. In: Safar ME, O'Rourke, MF, editors. Arterial stiffness in hypertension. Vol 23. Amsterdam: Elsevier; 2006. pp. 427-456.

34 Kampus P, Kals J, Ristimae T, Fischer K, Zilmer M, Teesalu R. High-sensitivity $\mathrm{C}$-reactive protein affects central haemodynamics and augmentation index in apparently healthy persons. J Hypertens 2004; 22:1133-1139.

35 Kullo IJ, Seward JB, Bailey KR, Bielak LF, Grossardt BR, Sheedy PF 2nd, et al. C-reactive protein is related to arterial wave reflection and stiffness in asymptomatic subjects from the community. Am J Hypertens 2005; 18:1123-1129.

36 Mahmud A, Feely J. Arterial stiffness is related to systemic inflammation in essential hypertension. Hypertension 2005; 46:1118-1122.

37 Mattace-Raso FU, van der Cammen TJ, van der Meer IM, Schalekamp MA, Asmar R, Hofman A, Witteman JC. C-reactive protein and arterial stiffness in older adults: the Rotterdam Study. Atherosclerosis 2004; 176:111116.

38 Vlachopoulos C, Dima I, Aznaouridis K, Vasiliadou C, loakeimidis N, Aggeli $\mathrm{C}$, et al. Acute systemic inflammation increases arterial stiffness and decreases wave reflections in healthy individuals. Circulation 2005; 112:2193-2200.

39 Yasmin, McEniery CM, Wallace S, Mackenzie IS, Cockcroft JR, Wilkinson IB. C-reactive protein is associated with arterial stiffness in apparently healthy individuals. Arterioscler Thromb Vasc Biol 2004; 24:969-974

40 Diamant M, Lamb HJ, van de Ree MA, Endert EL, Groeneveld Y, Bots ML, et al. The association between abdominal visceral fat and carotid stiffness is mediated by circulating inflammatory markers in uncomplicated type 2 diabetes. J Clin Endocrinol Metab 2005; 90:1495-1501.

41 Boreham C, Savage JM, Primrose D, Cran G, Strain J. Coronary risk factors in schoolchildren. Arch Dis Child 1993; 68:182-186.

42 Gallagher AM, Savage JM, Murray LJ, Davey Smith G, Young IS, Robson PJ, et al. A longitudinal study through adolescence to adulthood: the Young Hearts Project, Northern Ireland. Public Health 2002; 116:332-340.

43 van Lenthe FJ, Boreham CA, Twisk JW, Savage MJ, Murray L, Smith GD. What determines drop out in prospective studies of coronary heart disease risk factors between youth and young adulthood: the Young Hearts Study. J Epidemiol Community Health 2001; 55:681-682.

44 Matthews DR, Hosker JP, Rudenski AS, Naylor BA, Treacher DF, Turner RC. Homeostasis model assessment: insulin resistance and beta-cell function from fasting plasma glucose and insulin concentrations in man. Diabetologia 1985; 28:412-419.

45 Boreham CA, Ferreira I, Twisk JW, Gallagher AM, Savage MJ, Murray LJ. Cardiorespiratory fitness, physical activity, and arterial stiffness: the Northern Ireland Young Hearts Project. Hypertension 2004; 44: $721-726$.

46 Brull DJ, Murray LJ, Boreham CA, Ralston SH, Montgomery HE, Gallagher $\mathrm{AM}$, et al. Effect of a COL1A1 Sp1 binding site polymorphism on arterial pulse wave velocity: an index of compliance. Hypertension 2001; 38:444-448.

47 Woodside JV, McMahon R, Gallagher AM, Cran GW, Boreham CA, Murray $L J$, et al. Total homocysteine is not a determinant of arterial pulse wave velocity in young healthy adults. Atherosclerosis 2004 177:337-344. 
48 Andersen LB, Boreham CA, Young IS, Davey Smith G, Gallagher AM, Murray L, McCarron P. Insulin sensitivity and clustering of coronary heart disease risk factors in young adults. The Northern Ireland Young Hearts Study. Prev Med 2006; 42:73-77.

49 Brage S, Wedderkopp N, Ekelund U, Franks PW, Wareham NJ, Andersen LB, Froberg K. Features of the metabolic syndrome are associated with objectively measured physical activity and fitness in Danish children: the European Youth Heart Study (EYHS). Diabetes Care 2004; 27:2141-2148.

50 Schiffrin EL. Vascular stiffening and arterial compliance. Implications for systolic blood pressure. Am J Hypertens 2004; 17:39S-48S.

51 Weber T, Auer J, O'Rourke MF, Kvas E, Lassnig E, Berent R, Eber B. Arterial stiffness, wave reflections, and the risk of coronary artery disease. Circulation 2004; 109:184-189.

52 Safar ME, Levy BI, Struijker-Boudier H. Current perspectives on arterial stiffness and pulse pressure in hypertension and cardiovascular diseases. Circulation 2003; 107:2864-2869.

53 Hak AE, Pols HA, Stehouwer CD, Meijer J, Kiliaan AJ, Hofman A, et al. Markers of inflammation and cellular adhesion molecules in relation to insulin resistance in nondiabetic elderly: the Rotterdam study. J Clin Endocrinol Metab 2001; 86:4398-4405.

54 Han TS, Sattar N, Williams K, Gonzalez-Villalpando C, Lean ME, Haffner SM. Prospective study of C-reactive protein in relation to the development of diabetes and metabolic syndrome in the Mexico City Diabetes Study. Diabetes Care 2002; 25:2016-2021.

55 Rutter MK, Meigs JB, Sullivan LM, D'Agostino RB Sr, Wilson PW. $\mathrm{C}$-reactive protein, the metabolic syndrome, and prediction of cardiovascular events in the Framingham Offspring Study. Circulation 2004; 110:380-385.

56 Sarafidis PA, McFarlane SI, Bakris GL. Gender disparity in outcomes of care and management for diabetes and the metabolic syndrome. Curr Diabet Rep 2006; 6:219-224.

57 Nichols WW, O'Rourke MF. McDonald's blood flow in arteries: theoretical, experimental and clinical principles. 4th ed. London: Edward Arnold; 1998.

58 Franklin SS. Arterial stiffness and hypertension: a two-way street? Hypertension 2005; 45:349-351.

59 Mahmud A, Feely J. Adiponectin and arterial stiffness. Am J Hypertens 2005; 18:1543-1548.

60 Singhal A, Farooqi IS, Cole TJ, O'Rahilly S, Fewtrell M, Kattenhorn M, et al. Influence of leptin on arterial distensibility: a novel link between obesity and cardiovascular disease? Circulation 2002; 106:1919-1924. 